\title{
Sexism of the Jiko (Cooking Stove), Food and Sexuality: The Fuzzy Conceptual Boundary
}

\author{
Magonya Achieng' Lilian
}

Department of Linguistics, Maseno University, Kenya

Copyright@2019 by authors, all rights reserved. Authors agree that this article remains permanently open access under the terms of the Creative Commons Attribution License 4.0 International License

\begin{abstract}
This paper re-examines the Jiko ${ }^{1}$ as a symbol of femininity within the East African region. In the Kenyan society, jikos serve as charcoal based ceramic stoves used for cooking in virtually all households. The goal of this paper is to infuse arguments which interface cognitive linguistics and sociolinguistics, in an attempt to unveil sexist terms coined around the jiko and further drawing on metaphoric extension, reveal how sexist expressions are cognitively interlaced with the semantic domains of marriage, sexuality and the female anatomy.
\end{abstract}

Keywords Jiko, Food, Metaphors, Sexisms, Sexuality and Female Anatomy

\section{Introduction}

Sexism is a social problem...to eliminate sexist language calls for eliminating the concept of prejudice in human beings (Lei, 2006:94)

According to Hugh (1991) and Kinyanjui and Childers (1983) the Jiko is a charcoal burning ceramic stove originally designed from a Thai bucket stove. It is virtually used in over $50 \%$ of urban and peri-urban households in Kenya. This is credited to its energy saving attributes associated with its ceramic heat retaining liner. From a linguistic perspective, the term Jiko has a Kiswahili etymology, and most women use it for cooking food in the kitchen. Interestingly, when the Kiswahili bound morpheme -ni is appended on the root of Jiko, the Kiswahili term known as Jikoni which denotes a kitchen is coined. In the African context, cooking is one of the key gender roles that epitomizes a true African woman. Said differently, whenever a man marries a woman, the Kiswahili expression amepata jiko (He has found a

1 A Jiko is a Kiswahili term used in reference to a ceramic cooking stove. Kiswahili is a Bantu language spoken in the East African region as a lingua franca. cooking stove) is used in reference to finding a spouse. This by metaphorical extension means that he has found someone to cook for him (Kiango, 2003; Ndimande-Hlongwa and Rushubiriwa, 2014; Chege, Onyango and Gwachi, 2016). To be emphatic on the aforementioned point, Ndimande-Hlongwa and Rushubiriwa (2014:400) express the following thoughts

The Jiko reflects the image of a woman in marriage....A woman is seen as a cook, stove or a kitchen, which is used to cook food for a man and the family. In this case, it is a woman's responsibility to make sure that her husband eats well and properly. Thus the place of a wife is in the kitchen (cf. Wenje, 2015)

Hence from the above quote, such an observation would provide insights on the origin of sexist expressions pervasive in many African societies such as a woman's place is in the kitchen and even more recently within the social media, a quote attributed to the former President of Zimbabwe Robert Mugabe quote resonates with Wenje (2015) in the following statement My brothers, marry a woman who can cook, do not marry for love or beauty. Because love dies and beauty fades, but hunger remains. At this point, it is imperative to emphasize that cooking metonymically overshadows other feminine gendered roles such as raising children or doing other domestic chores. Moreover, it represents the primary role of the African women in matrimony, which traditionally has been to cook well for her husband. As a matter of fact, in African traditional societies, any woman with sub-standard culinary skills was sent away by her in- laws to her parents, so as to enable her refine her culinary skills. Therefore, by the time a girl reached puberty, she would be progressively inducted into the art of cooking, so that by the time she gets married, she would have transformed into an excellent cook. Linguistically, she would be motivated by expressions like the best way to a man's heart is through his stomach. Hence, this was to serve as a deterrent so that the woman strives to be an excellent cook to safeguard her marriage, by not embarrassing her parents for being a horrible cook. In fact, drawing from el-Aswad (2014: 41) in the Arabic world, it was an insult for a woman to be 
labelled a bad cook. Indeed, such a mental imagery of women as cooks is not confined to the Kiswahili language, but is evident in a number of African languages spoken in Kenya as shown in the Table 1 . The data collected was obtained from 6 postgraduate students of Maseno University in Kenya, who were pursing Linguistics. The researcher casually asked the respondents to provide the lexical terms for the expressions to marry and to get married in their native languages. Further, they were to state whether such terms overtly depicted gender roles. The lexical terms were drawn from the following Kenyan speech communities; Luo, Luhya (particularly Bukusu and Lwikato dialects), Kalenjin, Ekegusii and Teso Communities as shown in Table 1.

Table 1. The terms to marry and to get married from selected Kenyan communities

\begin{tabular}{|c|c|c|}
\hline Speech Community & $\begin{array}{c}\text { To marry } \\
\text { ( In reference to the male gender) }\end{array}$ & $\begin{array}{c}\text { To get married } \\
\text { ( In reference to the female gender) } \\
\end{array}$ \\
\hline Luo & $\begin{array}{l}\text { Kendo, Nyombo ( To marry, no overt gender } \\
\text { role in the two words) }\end{array}$ & $\begin{array}{l}\text { Dhi Tedo- ( She has gone to cook for someone), or } \\
\text { Onyuome ( She is married) }\end{array}$ \\
\hline (a) Luhyia (Lwikato Dialect) & $\begin{array}{l}\text { Khuteshia- To make one cook for a man, since } \\
\text { the man is supposed to be served by the woman. } \\
\text { The man is also supposed to protect the woman }\end{array}$ & $\begin{array}{l}\text { Khutekha-She has gone to cook and perform } \\
\text { chores reserved for women }\end{array}$ \\
\hline (b)Luhyia (Bukusu dialect) & $\begin{array}{l}\text { Khuila Omukhasi- To acquire a cook/ He is } \\
\text { married }\end{array}$ & $\begin{array}{l}\text { Omukhana Kachile Khutekha- She has gone to } \\
\text { cook }\end{array}$ \\
\hline Kalenjin & Kitunis- He has brought a cook & Kwondo- She has gone to cook, especially Ugali ${ }^{2}$ \\
\hline Ekegusii & $\begin{array}{l}\text { Konyonwa- To marry } \\
\text { Omusacha-A husband, one who looks for } \\
\text { wealth. }\end{array}$ & $\begin{array}{l}\text { Konyomwa- To get married } \\
\text { Omurongi one- The one who cooks and reference } \\
\text { is made to Ugali }\end{array}$ \\
\hline 5. Teso & $\begin{array}{l}\text { Adukokin- By paying dowry the man has } \\
\text { formally invited the woman to his home, the } \\
\text { woman becomes a man's property/possession } \\
\text { and marriage is symbolised having a home }\end{array}$ & $\begin{array}{l}\text { Adhukhokhina-A married woman is seen to have a } \\
\text { home, a kitchen to cook and she is now a member } \\
\text { of a new clan. In short a woman's place is in the } \\
\text { kitchen }\end{array}$ \\
\hline
\end{tabular}


From the five Kenyan communities, it is arguable that some words used in reference to marry or to be married clearly define a woman's gender role. In some cases, the male gender roles are either overt or covert. To begin with, Luo, which is a Nilotic language has the expression kendo or nyombo (to marry). Apparently, the term has no overt gender role for the male gender. However, the word Odhi tedo (She has gone to cook) used in reference to getting married, overtly gives prominence to cooking as a gender role affiliated to women. Nonetheless, it is important to state that the term Onyuome (she is married) does not overtly register the woman's gender roles. Second, the Luhyia community which is a Bantu language, there are two dialects which will be considered notably Bukusu and Lwikhato dialects. Lwikhato dialect has the expression Khuiteshia (to marry), it means that once a man has married a woman, the wife now takes charge of cooking within the homestead. Therefore, marriage compels the woman to cook for the man. Likewise, the man is also expected to protect the woman. In the same community, the term (to get married) shares the same meaning as the Luo term of Odhi tedo, where the woman is perceived as a cook in her home, and also she is expected to perform roles ascribed to her gender. The Bukusu dialect has the term Khuila Omukhasi (to marry) which translates literally as he has acquired a cook. Whereas, the term Omkhana khachile kuteka (to get married) implies that one has gone to cook. Kalenjin ${ }^{3}$ language has the expression Kitunis (to marry) and its literal translation is one who has brought a cook, whereas the term kwondo, means one who has gone to cook Ugali, which refers to a married woman At this point, it is important to mention that Ugali is a Kenyan staple food that is made from corn or millet flour, and most Kenyan women have to know how to cook it well. The Ekegusii ${ }^{4}$ language has the expressions Konywoma (to marry) and konyomwa (to get married) which do not overtly register the gender roles. Alongside such expressions, the same speech community has the term for a husband as omosacha meaning the provider and one who looks for wealth. While the term used in reference to a wife is omurungi one (meaning one who cooks ugali). It can be said that in both Kalenjin and Ekegusii languages emphasis is placed on the woman's ability to cook ugali as a benchmark for a true African woman. Then finally, among the Teso ${ }^{5}$, the expression Adukokin (to marry), which suggests once a man has paid dowry, he has formally invited the woman to his home to be his wife. While Adukhokina (to get married) implies that a woman now has a home, a place to cook and is also a member of a new clan or the husband's family. The Teso also subscribe to the thesis that a woman's place is in the kitchen. Apparently, this is a similar observation that was made by Ndimande- Hlongwa and Rushubiwa

3Kalenjin is a Nilotic language spoken in the Rift Valley region in Kenya 4Ekegusii is a Bantu language spoken in the Kisii county in Kenya

5 Teso is a Nilotic language spoken in Teso County in Kenya
(2014) and Wenje (2015). From the data, it can be deduced that in a number of Kenyan speech communities, the concept of marriage overtly confines an African woman's gender roles to cooking. The latter metonymically stand for all other roles assigned to the female gender. This leads us into discussions on language and sexism as conceptualized by Lei (2006), Cameron (2005), Nneka (2012) and Mmadike (2014).

\section{Language and Sexism}

According to Weatherall (2002), Lei (2006), He (2010) and Wardhaugh and Fuller (2015) language is a linguistic tool capable of moulding, shaping and representing societal realities. This is inclusive of construction of gender either in patriarchal or matrilineal societies. According to Chin (2009), Wardhaugh and Fuller (2015) and Njoroge, Mukhwana and Sanja (2016) such constructions represent underlying ideologies of what constitutes the behaviour, demeanor, gender stereotypes, appearance and designated gender roles for both men and women. Further, they advance the thesis that language plays a role in symbolic positions of men and women. For instance, in patriarchal societies, women are inferior to men as they are conceptualized as deviant, deficient and thus made invisible through language. Hence, making the language sexist. A sexist language expresses bias in favor of one sex, it is not only discriminative, but it endorses gender inequality, by favoring men as opposed to women and vice versa. For instance, Rodriguez (2009) argues that men are positively labelled as the sterner sex or stronger sex, whereas, women are termed as the fairer sex or weaker sex. For some scholars, sexism is related to societal attitudes towards a particular gender and this actually registers the perceived stereotyped images of how men or women should behave or act and even their demeanor. For instance, women are supposed to be submissive, homemakers and nurturers while men should be providers, strong, fearless and breadwinners, African women are supposed to be curvaceous or fat and not slender (cf. Cameron, 2005; Nneka, 2012; Mmadike, 2014). Sexist language manifests itself in various ways, first and foremost is through asymmetries in some words as listed as follows

\begin{tabular}{|l|l|}
\hline \multicolumn{1}{|c|}{ Male } & \multicolumn{1}{|c|}{ Female } \\
\hline $\begin{array}{l}\text { Master ( A male person who is in } \\
\text { charge) }\end{array}$ & $\begin{array}{l}\text { Mistress ( A clandestine } \\
\text { lover of a married man) }\end{array}$ \\
\hline $\begin{array}{l}\text { Governor ( A political title for a man } \\
\text { who is in charge of a political } \\
\text { jurisdiction) }\end{array}$ & $\begin{array}{l}\text { Governess ( a woman } \\
\text { who takes care of } \\
\text { children) }\end{array}$ \\
\hline Sir ( A respectable title for a man) & $\begin{array}{l}\text { Madam ( A woman who } \\
\text { runs a brothel) }\end{array}$ \\
\hline
\end{tabular}

(Source: Lei, 2006, He, 2010)

However, as stated by Yusuf (2002) first, titles such as master, sir and governor which are accorded to the male 
gender are positive whereas terms like queen, madam, lady and dame are to some extent pejorative since they are associated with both prostitution and fornication. Second, the use of generic terms such as man or guys where either gender is covered, for example All men are equal and You guys come here (Romaine, 2005). Third, there are female surnames derived from male surnames such as Pauletta from Paul, Georgina from George or even professions such as actress for actor, poetess from poet. Fourth, there are sexist proverbs such as in Turkish Let the one who bears a son be proud and the one who bears a daughter beat himself. Indeed, such a proverb only takes pride in the birth of the boy child. For Romaine (2005) in a patriarchal society, a sexist language is designed for men by men. Said differently, this is meant to propagate the ideology that subdues women as the weaker sex. Romaine opines that gender-based stereotypes are a set of beliefs that prescribe gender roles in a given society, such stereotypes are communicated and enacted through language. Waudhaugh and Fuller (2015) further argue that sexism is interlaced with prevailing social and moral order so as to advance culture-specific ideologies on gender roles. Moreover, for Weatherall (2002), even using non -sexist language does not automatically translate into a non-sexist society. In view of this, one can only remain hopeful that members of a speech community can deconstruct sexist ideologies existing in their same language. This explains recent attempts made to coin gender neutral terms such as human kind instead of mankind and chairperson instead of chairman (cf. Romaine, Weatherall, 2002; Romaine, 2005 and Waudhaugh and Fuller (2015). According to Lei (2006), sexism is enshrined in societal attitudes towards a particular gender and eliminating it calls for shunning such attitudes which in reality might be a daunting task considering they have been in existence for centuries. From the foregoing, it can be said that the jiko as the cooking stove generates sexist terms.

\section{Food, Women and Sexist Language}

In the introductory sections of this paper, the literature affirms that women are the key custodians of the kitchen. From a cognitive linguistics perspective, we conceptualize phenomenon based on our embodied experience with concepts. Given that women are basically perceived as cooks in a number of African cultures, it means that there are a number of foods which are used metonymically in reference to women. Hines (2000), El-Aswad (2014) and Fox (2014) concur that cooking is synonymous with the female gender in many societies, whereby women are generally expected possess excellent culinary skills. In fact, Fox (2014) adds that in Western cultures, a bride would be appraised for her culinary skills in baking cherry pies. Furthermore, according to el-Aswad, in the Arabic culture, culinary skills were more valued than virginity as cooking epitomizes feminity. In Hines (2000), Chin (2009) and Khajeh and Abdullah, (2012) perspectives, food, women and sexuality are linked under LUST IS FOOD or HUMAN BEINGS ARE FOOD conceptual metaphors. Labovitz (2005) cites a rabbi who states that ... Just as food is necessary for sustaining life, so too sex is linked to perpetuation of humanity. Surprisingly, a similar view is held by Rodriguez (2014), Fox (2014) and even Goatly (2007:90) as cited in Hines (2000) who neatly unpacks it as follows

If we do not eat we die, if we have no sex, we simply fail to reproduce and human race eventually dies. Equating sex with eating might suggest that sex is essential for our life. More specifically, the sole purpose of women is to satisfy the appetites of men, just as food is produced for the sole purposes of eating.

For Lakoff (1987: 409) as cited in Hines (2000) and Khajeh and Abdullah (2012) sexual desire emanates from the body as one hungers for a member of the opposite sex. Put differently, the person is conceptualized as food. Moreover, Hines (2000), Labovitz (2008), Chin (2009) and Murashova and Pravikora (2014) opine that women are equated to sex objects and this commodification of women as foods (cupcake), objects (for example in Labovitz (2008), the following statement was drawn from Rabbinic literature. A man should not drink from one cup and have his eyes on another cup $^{6}$, the expression equates women to a cup as an object) or animals like tigress or fox diminishes their status while men assume a dominant position. Said differently, women are perceived as powerless and inanimate, whereas men as seen as lions or bulls among other zoosemic metaphors. Murashova\& Pravikova (2014) contend that objectification of women is enshrined in patriarchal practices and is associated with sexual or erotic characteristics of a woman's demeanor. A case in point is in ancient Greek, where women were not regarded as part of the human race, they were to be submissive, remain chaste till marriage, keep the family hearth and give birth to sons. They further add that a woman is described in terms of fertility and reproduction, she is supposed to produce young ones as well as support and defend her spouse. Therefore, women actually identify themselves with images propagated by a patriarchal ideology such as images of a mother, a virgin, a femme fatale or even a prostitute, all whom are subject of a man's desire. Ruiz \& Herroro (2006), Rodriguez (2009), Rodriguez (2014) argue that the objectification or dehumanization of women can be clearly explained using the GREAT CHAIN OF BEING conceptual metaphor structured as follows

6Labovitz (2008: 162) holds the thesis that in American or western societies, women are more vulnerable than men, and that their bodies are more permeable than men. This makes men dominant and women subordinate. Therefore, the image created of a woman as a vessel such as a cup, suggests that men can easily reach the object and consume its contents as he desires. Therefore, the woman satisfies a man's sexual needs and fantasies. 


\section{God $\boldsymbol{V}$ Human beings $\rangle$ Animals $\rangle$ Plants $\rangle$ Complex objects $\rangle$ Natural physical things}

In the hierarchy, each level is characterized by having properties that define the lower one, but also accommodates additional distinct traits. By the GREAT CHAIN OF BEING metaphor, we understand human attributes correspond to animals or plants as in the expression She is a sly fox or the pretty little girl is such a flower. Rodriguez (2009) adds that within each level, there are sub -levels of different power relations. For instance, under the animal category, the lion is on a higher scale than a mouse. Therefore, for Rodriguez (2014), the moment one assigns features of a lower hierarchy to human beings such as objects or natural physical things, it is tantamount to degrading or dehumanizing one, especially in contexts where women are equated to food hence reducing them to edible things which are in the lower position of the chain. Murashova and Pravikova (2014) infuse Freudian thoughts on THE GREAT CHAIN OF BEING metaphor by suggesting that besides animals other objects such as flowers, fruits, different artifacts and objects can be associated with sexual symbolism. Taking the case of flowers as a part of a plant, some girls' first names such as Daisy, Jasmine, Rose, Ivy, Violet and Lily are used in reference to the female gender. Besides this, the image of a flower evokes the image of a defenseless beautiful creature which requires protection. There are floral metaphors used in reference to puberty, maturity, first sexual experience, menstruation, pregnancy and motherhood. For instance, rosebud is a beautiful or blossoming lady, to bloom denotes maturity, to deflower is euphemistically used in reference to the rupturing of the hymen, flowering denotes sexual maturity and to cop cherry means to be intimate with a virgin. Given that our focus is on food, Hines (2000) and Yusuf (2002) argue that endearment terms such as honey pie, cupcake, tart, pudding pie are hosted by A WOMAN IS A DESSERT metaphor (cf. Montashery, 2013;. Murashova, Pravikora, 2014, Kowalczyk, 2015) , in the sense that women can be bought and sold, eaten, elaborately decorated as in the case of frosting that describes the make-up of a beauty pageant contestant, who can be admired for her physical appearance but dismissed as sinful and decadent. In this regard, women are perceived as objects of lust, hence the linguistic expression she is so sweet or she is a nice piece of pie used euphemistically instead of the expression she is a nice piece of ass. For Rodriguez, this implicitly indicates deficiency which relegates women to the level of things in the CHAIN OF BEING conceptual metaphor. However, Montashery (2013: 108) perceives it as use of metonymy, where the female anatomy is fragmented into parts, this not only depersonalizes, but objectifies a woman's body into parts as manifested in expressions used in reference to women such as sugar cheeks, sugar lips and sweet cheeks among others. Hines frames WOMAN AS DESSERT metaphor as follows.

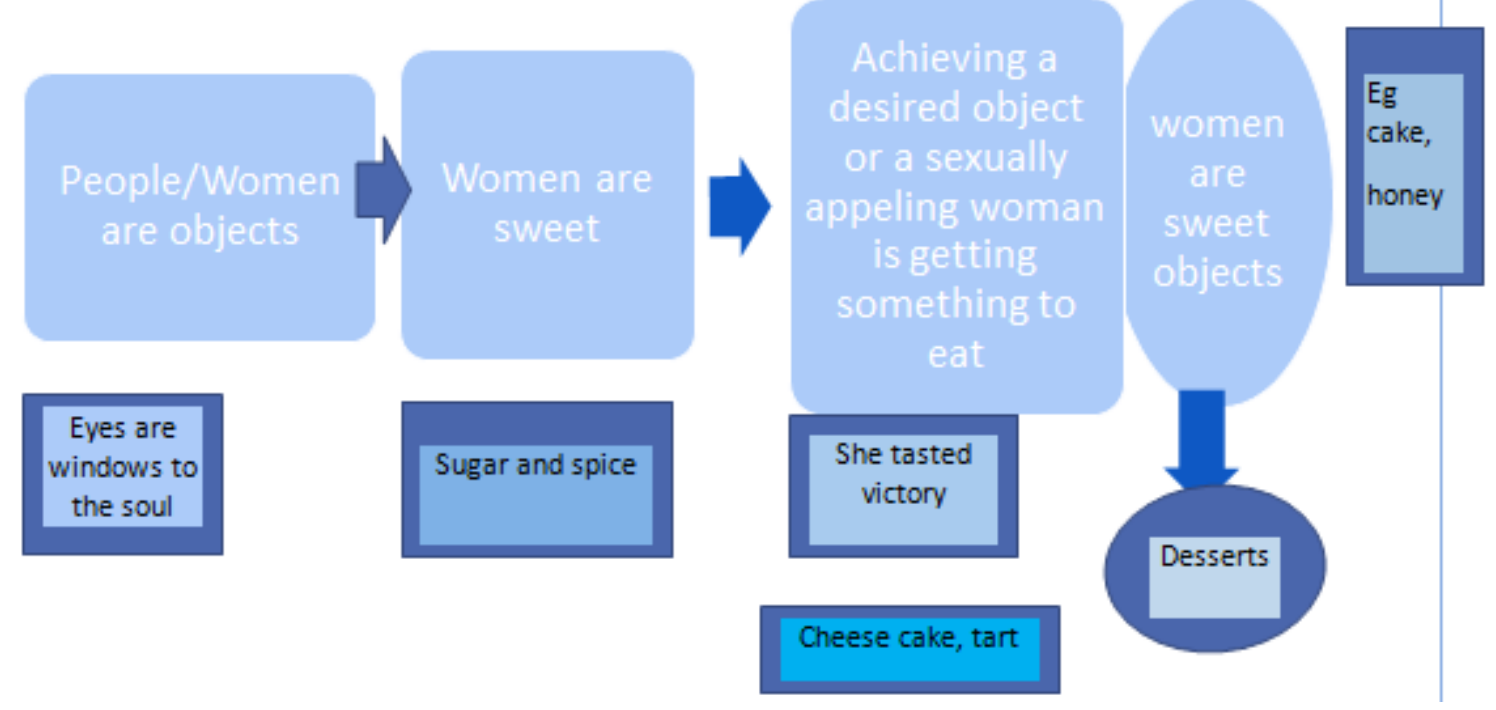

Figure 1. Evolution of WOMAN AS DESSERT metaphor- a revised model ${ }^{7}$ (Hines,2000: 147) 
Hines (2000) and Chin (2009) argue that endearment terms coined around women focus on their physical beauty or attractiveness, ugliness or unattractiveness body parts such as the genitalia or bust and sexuality, as shown in the following examples drawn from English in Hines work and Chinese in Chin (2009) which focus on physical appearance, sexual appeal and the female genitalia.

Tart- A pleasant and attractive woman, a prostitute or loose woman, girl (sister or daughter)

Pie- The sexual perception of a woman, nice piece of pie as a slang euphemism for nice piece of ass

Female genitalia and promiscuity

Jelly : Slang for lover and female genitalia

Cherry-A sexually promiscuous woman and also a euphemism for the hymen

Cookie, Cookie jar-Denotes the vagina, vulva, dear, sweetheart,

Melon (in Arabic)- Virginity (el-Aswad, 2014)

Pork chop: A fat, ugly and a sexually undesirable woman

Steak: A fat, ugly and sexually undesirable woman

\section{Bust:}

Big bust: English Slang Water melon (Chin, 2009)

Small bust: Lemons, grapes, apples (Chin, 2009)

Bust: Pears (Rodriguez, 2014)

Bust: Avocadoes in Kikuyu ${ }^{8}$ (Njoroge, Mukhwana and Sanja, 2016)

Bust: (Chinese) Meatballs (Chin, 2009)

Huge Bust: (Chinese) E/G Milk or Gigantic milk or Milk cow: A woman with a huge bust. In Chinese, milk metonymically represents the breast, given that it is secreted from the mammary glands. (Chin, 2009)

From the foregoing, it is evident that foods used in reference to women touch on their appearance, dressing, sexuality and their genitalia. In fact, for Hines (2000) and Yusuf (2002), linguistic chauvinism can convert a woman into a prostitute in any context as seen in certain words such as tart cookie, cherry, pie and so on. According to Varriano (2005) since the renaissance, fruits and vegetables visual metaphors have been exploited in their artistic work to represent images of the human anatomy, for instance, eggplants to represent the testicles and sliced water melons to represent the vagina in artistic works. The interface between food and sexuality is extensively discussed in the next section

\section{Food and Sexuality}

Fox (2014:2) asserts that "animals eat but we are the only animal that cooks. So cooking becomes more than necessary, it is the symbol of our humanity, what marks us off the rest of nature". Fox further suggests that feeding, seduction or courtship are interlaced, he cites the case of

8Kikuyu is a Bantu language spoke in central Kenya the praying mantis where the female devours the male after mating, this is because after the male praying mantis has completed his reproductive task, he immediately converts into a food source for the now expectant female praying mantis. Fox infuses additional arguments from human cognition to explain how food and sexuality are related, he states that food and sex are physically linked in the limbic system of the brain, responsible for controlling emotional activity in the body. Particularly, it is the sensuality of eating which makes it pleasurable. In another perspective, a man is supposed to be a provider and even during courtship, he is supposed to invest in the female by buying food. Here, a man who offers a meal to his girlfriend is considered to be engaging in foreplay. After intimacy, the woman is expected to make breakfast for the man to complete her side of the bargain. Therefore, Fox suggests in courtship or dating food is seen as a prelude to sex. In Labovitz (2008) and Rodriguez (2014) perspectives, the intricate web of food and sex can be used in reference to sexual activity, sexual partners, sexual desire which is conceptualized as hunger under DESIRE IS HUNGER conceptual metaphor as in the expression $I$ am hungry for you or even a man's genitals being referred to as sausage. Rodriguez (2014) opines that there is a correlation between eating and human desire, where desire is perceived as hunger for food and the object of desire is represented as food. Said differently, hunger and eating express sexual desire. Apparently, similar metaphors were not only used during the renaissance, but were employed in Greco- Roman and early Judeo-Christian cultures (Varriano, 2005). In fact, for Labovitz, anthropologists, psychologists and even linguists have culturally linked the food metaphor to sex, sexuality and gender. Said differently, food as a source domain can be mapped onto the target domains of sexual partners, sexuality and sexual organs. This means that food items serve as the source of metaphorical transfers, which structure sexual behaviors as acts involving an agent (the one who eats) and the object of the agent's activity (the food being consumed). In most cases, it is the man who is the agent, and the woman is the food being eaten. However, Labovitz study of food metaphors in Rabbinic literature observes that in Torah, eating together denotes sexual acts as in the following extract Labovitz (2008: 182) from Ketuboot 5:9

He gave her silver ma'ah (coin) for her needs, and she eats with him from the eve of the Sabbath to the eve of the Sabbath (that is every week, or every Sabbath eve)

Here eating together denotes sexual acts or intimacy among couples. According to Khajed and Abdullah (2012) who undertook a cross -cultural study on Persian culinary metaphors by focusing on THOUGHT AS FOOD, TEMPERAMENT AS FOOD and LUST AS FOOD, contend that food plays a central role in any culture, given that it is a source of nourishment and pleasure. From a cognitive linguistics perspective, food as a source domain can be mapped onto various domains such as virtue, 
temperament and sexual desire. Therefore, we tend to enjoy tasty foods while shunning tasteless ones. Drawing insights from the Asner's Conceptual mapping Theory, they use the following model to present possible mapping and sub- mapping patterns that encourage cross- domain mappings between food as a source domain and other related target domains. Whereby, food as a source domain can be mapped onto a culture specific target domain such as thought, temperament or even sexuality by ensuring that there is metaphorical correspondence between the source domain and the world knowledge about the target domain. There are three key questions guiding our real world knowledge about food, whereby entities, qualities and functions are what determine the cross-domain mappings between the source domain and target

1. What attributes does the source domain (food) have? Essence/ Ingredient/ Entity

2. What qualities does the source domain (food) have? Flavour/ Taste

3. What does the source domain (food) do? (Function) Preparation/ Digestion )

Here the cross-domain mappings have the source domain as food whereas the target domain is that of lust or sexual as shown in Figure 2.

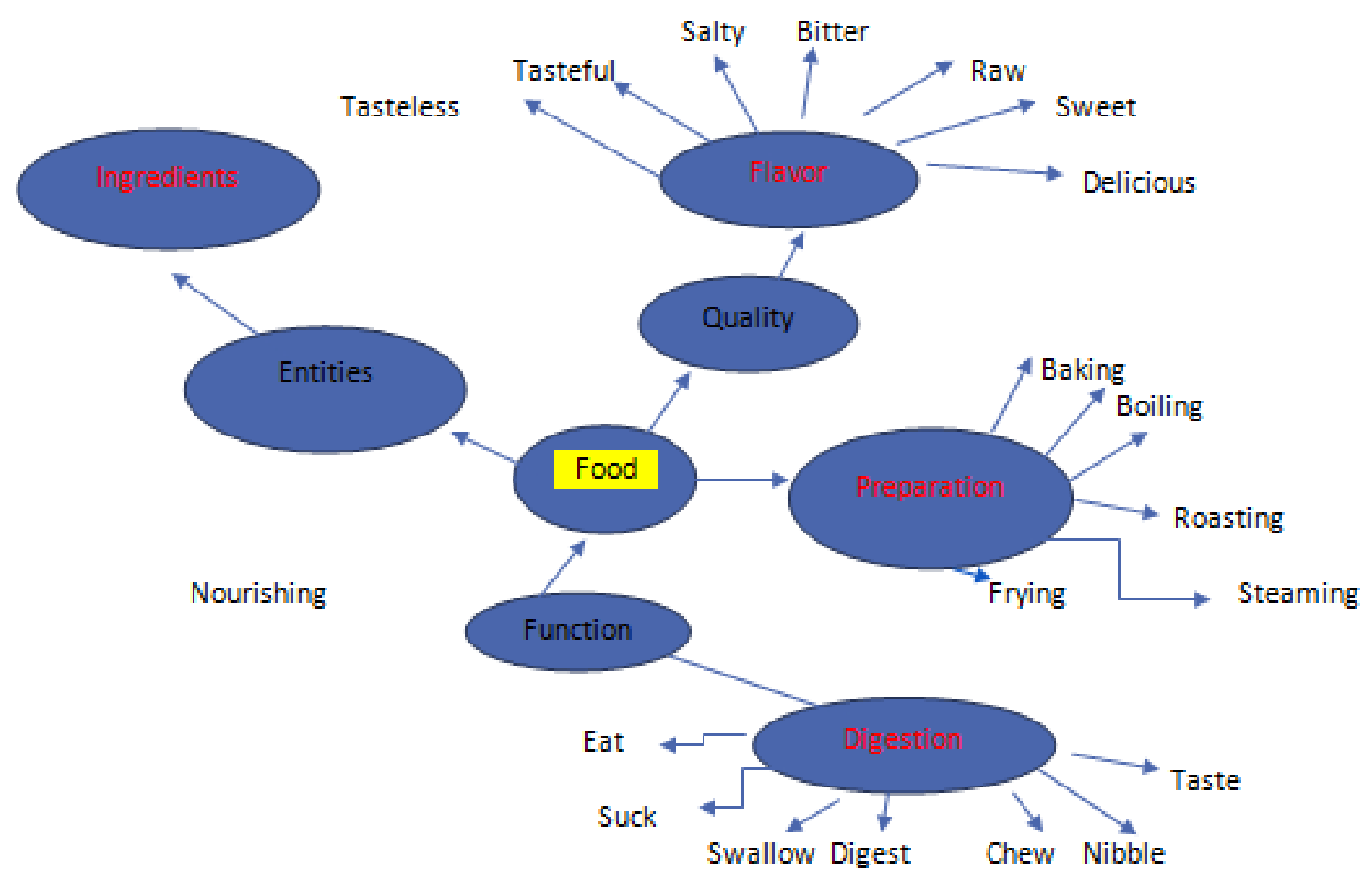

Figure 2. Cross -domain mappings of SEX IS FOOD conceptual metaphor

\section{Source domain (Food) Target Domain (Sexuality or Lust)}

Ingredient (Entity)

Flavour (Quality)

Preparation (Function)

Digestion (Function)
Boosting ones sex life, for example, Visit a sex therapist to spice your sex life.

Pleasurable intimate acts: Sweet kisses

Physical appearance: She has a bun in the oven (She is expectant)

Intimate sexual acts: He nibbled her lips, he devoured her, $\mathrm{Na}$

Nyame (I chewed her in the Luo language), His passion consumed her. 
In Figure 2, ingredients are necessary for any food preparation, and this is the domain where spices are listed. Therefore, in the sexuality domain, enhancing or boosting one's sex life is regarded as spicing it up. The context of quality or flavor can be mapped onto pleasurable intimate acts which can be labelled sweet as in His sweet kisses or caress. Then under preparation, there are various ways in which food can be prepared, these can be mapped onto physical appearance such as in the expression She has a bun in the oven, where the human body is conceptualized as a cooking stove such as the oven and once nine months have elapsed, and a baby is born, the expression used is the Bunny is out. Or in Kiswahili slang known as Sheng', the expression Huyo manzi ameiva meaning that lady is sexually appealing (This lady is ripe or The lady is ready for consumption). Finally, in a number of cultures, sexual acts are expressed using eating verbs, for example, in English, He nibbled her lips or nipples, he devoured or consumed her, while in Luo the expression Na nyame ( I chewed her) is used to denote that he had sex with a particular lady. Gathigia, Ndungu and Njoroge (2015) use a similar expression like the Luo as in Küriã kigwa for sex which literally translates as chewing sugarcane or the expression küria irio which means eating irio, the latter is a delicacy among the Kikuyu. The sugarcane or irio metaphor could be metaphorically associated with sexual pleasure. While in Yoruba ${ }^{9}$ language, Yusuf (2002) observes the use of the term cop in Nigerian pidgin, which literally means to eat a woman, whereby having intercourse with a woman is construed as eating her. In Khajeh and Abdullah's perspective (2012), there are relatively few food metaphors used in reference to the male gender as opposed to the female gender, and they concur with Hines (2000) that equating women to food depicts them as victims, lifeless, passive in sex which out rightly downgrades the female gender. As matter of fact, Murashova and Pravikora (2014) the food conceptual metaphor registers a sexually exploitative attitude towards women.

In a different study but still within the context of food and sexuality, Faycel (2012) studies food metaphors used in Tunisian Arabic by focusing on HUMAN BEING IS FOOD conceptual metaphor, EMOTIONS ARE FOOD conceptual metaphor and LIFE IS FOOD conceptual metaphor. While studying the HUMAN BEING IS FOOD metaphor, Faycel (2012) and Rodriquez (2014) argue that there are several experiences associated with food, notably smelling, hunger, thirst, eating, tasting, chewing, swallowing, devouring, choking, digesting, vomiting, spitting, desiring, being satiated, excreting, cooking and preparing. These experiences are applicable in the conceptualization of human affairs which either describe human traits and socio-cultural values. For example,

9 Yoruba belongs to the Congo-Kordofanian language family and is spoken in Nigeria.
Rodriguez contends that life is conceptualized as food (variety is the spice of life), making a living ( to earn ones daily bread by hawking), gender (beef cake), sexual orientation ( canned fruit), personality (sweet), nationality or ethnicity (rice eaters, jorabuon- the potato eaters which is a Luo word used in reference to the Kikuyu ${ }^{10}$ community), or body parts (cucumber for the penis or apples for body shape) and even in the domain of spirituality (The biblical verse was spiritually nourishing).

Faycel (2012) stipulates that the food domain has been extensively used in the conceptualization of human moral traits. Such that foods in their raw or cooked states can comfortably describe human traits as in the following expressions Those are half-baked graduates or Let him fry in his own mistakes. Moreover, the sweet tasting foods provide positive models for conceptualizing human traits. The food domain furnishes various domains such as personalities, experience, love and emotion/reason. To begin with personality, in Tunisian Arabic, people's embodied experiences with certain foods can be used in reference to obedience and obstinacy under A DISOBEDIENT PERSON IS DIFFICULT TO MANIPULATE FOOD and AN OBEDIENT PERSON IS AN EASILY MANIPULATED FOOD conceptual metaphors. Experienced people are conceptualized as well cooked foods as in the following Kiswahili expression Huyo ni mwanamke aliyetokota akaiva (which literally translates as that woman is well cooked to suggest that she is a mature woman). In the context of love, kindness, generosity and hate, the following conceptual metaphors exist LOVE/KINDNESS IS SWEET FOOD, HATE IS BITTER and also SWEET IS GOOD and BITTER IS BAD in the context of wickedness, for example, in English one can say, She has such a sweet personality or .Her demeanor left a bitter taste in my mouth.

More recently, Kowalczyk $(2015,2016)$ has revisited foodsemic concepts, where food metaphors are metaphorical extensions which either refer to the male or female genitalia. She argues that metaphorically foodstuffs, serve as the source domain which are mapped onto their target domain notably human beings. Such mappings are guided by attributes from various domains such as domains of taste (bitter, sweet, sour), domains of consistency (with attributes such as juicy, spongy, dry, sticky, smooth, even, uneven, loose or lumpy) and finally, the domain of function. Kowalczky argues that a number of foods emic English verbs and nouns are euphemistically used in reference to sexual intercourse such as spoon, juice, milk, bun, nut, pancakes, make cheese and have a cup of tea, sandwich and toast. She argues that there are a number of foods used in reference to the female genitalia under the following six categories of female private parts, vagina, labia, vulva, pubic hair and hymen.

10 This is a Bantu language spoken in Kenya 
Table 2. Female privy parts viewed foodsemically

\begin{tabular}{|c|c|c|c|c|}
\hline \multicolumn{2}{|c|}{ Metaphorical sense } & \multirow{2}{*}{$\begin{array}{c}\text { Lexical items } \\
\text { Bun, cookie, mutton, meat, candy, beaver pie }\end{array}$} & \multicolumn{2}{|r|}{ Example in context } \\
\hline 1. & Female privy parts & & 1. & You turtle did you see her bun last night \\
\hline 2. & Vagina & $\begin{array}{l}\text { Bread, muffin, honey box, jelly roll, } \\
\text { cauliflower, oyster, juice box, lunch box, cake, } \\
\text { cake hole, golden doughnut, apple, apricot, } \\
\text { honey pot, bacon, a bit of meat, mutton, bean, } \\
\text { cabbage, fish cup of tea }\end{array}$ & $\begin{array}{l}1 . \\
2 . \\
3 .\end{array}$ & $\begin{array}{l}\text { Hey baby, can I butter your muffin } \\
\text { I give you my cauliflower any more } \\
\text { She is still a virgin, I bet she's got a totally } \\
\text { unopened lunchbox }\end{array}$ \\
\hline 3. & Labia & Beef curtains, meat curtains & 1. & $\begin{array}{l}\text { The former rock star event out partying at } \\
\text { the Bellagio in Vegas and showed the } \\
\text { world her hairless beef curtain because } \\
\text { she knows we just can't get enough of that }\end{array}$ \\
\hline 4. & Vulva & Pie & 1. & Dude, let’s go and get some pie \\
\hline 5. & $\begin{array}{l}\text { A red haired } \\
\text { woman's public hair } \\
\text { and vulva }\end{array}$ & Fire pie & 1. & Don't be shy...show us your fire pie \\
\hline 6. & Hymen & Cherry & 1. & $\begin{array}{l}\text { Associated with the growing heterosexual } \\
\text { awareness of high school students: cherry } \\
\text { means hymen, whereas cherry buster is a } \\
\text { deflowerer }\end{array}$ \\
\hline
\end{tabular}

Kowalczky (2015) broadly classifies foodstuffs into four categories notably

1) Baked products: bun, cake, cookie, cake-hole, golden dough nut, jelly roll, muffin pie.

2) Fruits: Apricot, apple, cherry.

3) Meat products: Beef, beef curtains, bacon, bacon, sandwich.

4) Miscellaneous and food related containers: fish, oyster, jelly, cup of tea, juice box, lunch box.

Kowalczky argues that the metaphorical transfers are guided by the following aspects, domain of taste, domain of function or domain of consistency. For instance, under the taste domain which hosts attributes of SWEET, is responsible for foodsemic transfers such as cake, bun, muffin, doughnut and so on. JUICY AND SWEET that are both under domain of taste and consistency is synonymous with fruits such as apple, apricot. For meat products, the underlying conceptual metaphor is ENGAGING IN SEX WITH A WOMAN IS CONSUMPTION OF MEAT, the same concept metaphorically extends to one's sexual partner. Further, the expression $a$ bit of meat denotes either sexual intercourse or a prostitute. The domain of function is manifested in lexical terms such a lunch box, cup of tea, jelly box, honeypot are housed under the container metaphor. This is because containers metaphorically align themselves to the sexual function played by the vagina during sexual intercourse. However, she argues that bean, cabbage, cauliflower cannot be catered for under their miscellaneous category. Nonetheless, we hold the thesis that the female genitalia is largely internal unlike the male genitalia which is external. This can be metaphorically presented by the way the pod encloses the bean, or how cabbages and cauliflowers are externally covered by layers of leaves. Interestingly, foodsemic transfer is applicable to men also where Kowalczky (2015) presents foodsemic transfers that focus on the male genitalia using four categories notably the penis, small penis, penis and testicles as shown in Table 3.

From Table 3, it is evident that meat products can be used in reference to the male genitalia under the schema of SEXUAL USE OF A PERSON IS CONSUMPTION OF MEAT conceptual metaphor. Then, there are metaphorical transfers dictated by the domain of size and domain of shape. This explains the metaphorical resemblance between penis and the following foods, banana, pear, peanut, cucumber and gherkin. Also, the domain of function, figuratively maps the lollipop and candy stick onto erotic acts between lovers. Kowalckyz $(2015,2016)$ stress that the foodsemic terms are used in colloquial language and serve as euphemisms

Besides use of foodsemic terms in reference to the human genitalia, female breasts and human anatomy have been described using fruits. In this regard, it becomes important to describe the female anatomy using fruits as a type of food to describe the bust and body shapes. Murashova and Pravikora (2014) contend that breasts are manifestation of femininity, and this is even evident in sign language, where the sign used to denote a woman are the two index fingers protruding from the chest, to represent the breast. Murashova and Pravikora add that breasts are sexual objects that symbolize fertility and sexuality. Based on their shapes, they have been compared to various fruits such as apples, cherries, coconuts, grapes, mangoes, lemons, milk wagons, milk containers and so on (cf. Kowalckyz, 2015). To add onto Chin's (2009) list of foodstuffs and fruits used in reference to breasts, Kowalcykz (2015) adds the following list on Table 4. 
Table 3. Foodsemic expressions used in reference to the male genitalia

\begin{tabular}{|cl|l|l|}
\hline \multicolumn{2}{|c|}{ Organ } & \multicolumn{1}{|c|}{ Lexical terms } & \multicolumn{1}{|c|}{ Examples of usage in context } \\
\hline $1 . \quad$ Penis & $\begin{array}{l}\text { Beef, meat, meat whistle, beef torpedo, beef bungle, hotdog, } \\
\text { love steak, meat puppet, sausage, salami pork sword, bacon, } \\
\text { pear, cucumber, gherkin, candy stick sugar stick, lollipop }\end{array}$ & $\begin{array}{l}\text { I think a man has gotta a bit large in } \\
\text { the meat department to get a waste } \\
\text { board effect } \\
\text { What're you going to do on the } \\
\text { variety show? Red wanted to know to } \\
\text { perform on a meat whistle }\end{array}$ \\
\hline $2 . \quad$ Small penis & Peanut & $\begin{array}{l}\text { Hey Holy,, have you seen the new } \\
\text { boy and his peanut? }\end{array}$ \\
\hline 3. & $\begin{array}{l}\text { Penis and } \\
\text { testicles }\end{array}$ & Fruit basket, bacon assegai, meat and two vegetables & $\begin{array}{l}\text { Tried to kick him in the fruit basket } \\
\text { least, not sure if I connected }\end{array}$ \\
\hline & Testicles & Nuts, beans, eggs, apricots, grapes, plums, chestnuts, & $\begin{array}{l}\text { Listen, if you don't let us in this } \\
\text { movie, I am gonna kick you square in } \\
\text { the nuts } \\
\text { I was playing football and got kicked } \\
\text { in the beans }\end{array}$ \\
\hline
\end{tabular}

Table 4. Foodstuffs associated with breasts

\begin{tabular}{|cl|l|l|}
\hline \multicolumn{2}{|c|}{ Breast size } & \multicolumn{1}{|c|}{ Lexical items } & \multicolumn{1}{c|}{ Examples in context } \\
\hline 1. & Female breasts & $\begin{array}{l}\text { Brownies, cakes, coconuts, apples, grapes, } \\
\text { mangoes, cupcakes, bacon bits, }\end{array}$ & $\begin{array}{l}\text { Man, I saw Rachael's coconuts last night. } \\
\text { Wow, look at her brownies. They look delicious. }\end{array}$ \\
\hline 2. & $\begin{array}{l}\text { Large female } \\
\text { breasts }\end{array}$ & $\begin{array}{l}\text { Melons, grapefruits. Watermelons, pumpkin, } \\
\text { heavy cream }\end{array}$ & Keira has nice melons. \\
\hline 3. & $\begin{array}{l}\text { Small female } \\
\text { breasts }\end{array}$ & Chestnuts, fried eggs & $\begin{array}{l}\text { Yeah, well rather disappointing chestnuts, he said } \\
\text { eyes locked onto the woman's breast. }\end{array}$ \\
\hline 4. & Female nipple & Strawberry, cherry & I played with the girl's strawberry last night \\
\hline
\end{tabular}

According to Kowalckyz (2015), terms used in reference to breasts include fruits (apples, grapes, lemons, melons), sweet food (brownies, cakes, muffins) and meat products such as bacon bits. The metaphorical transfers here have the attributive feature sweet, fleshy or succulent under the conceptual domain of taste and fruits are naturally regarded as sweet. The domain of shape banks on visual resemblance between the shape of the bust or its size and fruits like grapefruit, mangoes, melons, and watermelons. Therefore, under the domain of size, we can have large, average and small breasts are represented by fruits such as water melons, coconuts and chestnuts respectively. There is also another attributive value of round which denotes the visual resemblance of the breast. Besides breasts, fruits have been used to describe the female anatomy as noted by Posey (2012) and The Daily Mail (2014), the authors single out body types coined from fruit metaphors that are used in reference to the female gender as shown in Figure 3.

To explain Figure 3, rhubarb refers to women with small chests, slim hips and a straight body like for Kate Middleton, the Dutchess of Cambridge. Apple body shape refers to voluptuous women who have a big chest, a bit of tummy and slim legs like Queen Latifah. Double cherry body shape is characterized by a curvy chest and hips with a narrow waist, as in the case of the reality television star Kim Kardashian, then finally Pear shape describes a body type which women have larger lower and small upper bodies, with the hips slightly larger than the shoulders. Interestingly, men's body shapes can equally be described using vegetables as observed in the Daily Mail (2014) for instance, aubergine refers to a body shape characterized with a rounded shoulder and slim arms with a bit of tummy like in the case of the actor Vince Vaughn. Leek is used in reference to a body shape characterized by slim shoulders, hips and legs as in the case of Russell Brand's body and finally Beetroot denotes a body shape characterized with a large chest, tummy and narrow hips and legs and finally Parsnip denotes a body shape characterized with wide shoulders, wide chest and slim hips like David Beckham. In brief, fruit metaphors can be used to describe body shapes for men and women.

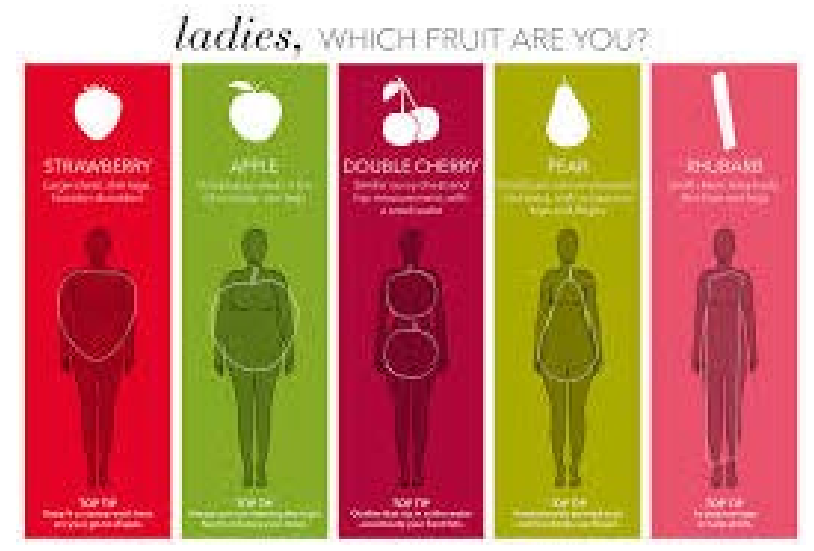

Source: The Daily Mail (2014)

Figure 3. Types of Body shapes for women 


\section{Conclusions}

Discussions in this paper highlight the following first, sexism is a truism in most patriarchal societies where women as the weaker sex are perceived as objects, food among others. Indeed, such terms conform to the Lakoffian to GREAT CHAIN OF BEING philosophy that outlines the tiers governing the objectification of women. However, modern scholars such as Kowalcykz research shows a paradigm shift whereby foodsemic terms can be used in reference to both genders in a sexist way. Second, sexist term portray a cognitive web that demonstrates the fuzzy conceptual boundary whereby the semantic domains of food, sexuality and sexism are metaphorically interlaced.

\section{REFERENCES}

[1] el-Aswad, el-Sayed(2014). Metaphors Arab women live by. Journal of Women of the Middle East and Islamic world (12)pp. 36-48

[2] Cameron, D. (2005). Language, gender and sexuality. Current Issues and New Directions. Applied Linguistics (26) (4). Pp 482-502.

[3] Chege, A. N, Onyango, O. J and Gwachi, M. (2016). "Gender Portrayal in Sexual Euphemism used in programmes Connect of K24 Television Kenya”. Scholars Journal of Arts, Humanities and Social Sciences 4 (5B) 537-542

[4] Chin, J. S. (2009). Are women nothing more than their body parts? Obscene and indecent metaphors used to describe women in Hong Kong magazine. In LCOM papers 2 (2009), $17-30$

[5] Counihan, D. (2005). The Anthology of food and the body. Gender, meaning and Power. New York: Routledge.

[6] Daily Mail (2014) Are you a parsnip or rhubarb? New Body Shape guide uses different fruits and vegetables to describe our figures. Website: Http://www.dailymail.co.uk/femail/a rticle-2589501/Are-parsnip-rhubarb-New-body-shape-guid e-uses-different-range-fruit-vegetables-figures.html. Consulted on $12^{\text {th }}$ January 2019

[7] Facyel, D. (2012) Food metaphors in Tunisian Arabic Proverbs. Rice Working Papers in Linguistics 3. Rice University URL http://hdl.handle.net/1911/64168.

[8] Fox, R. (2014). Food and Eating. An Anthropological Perspective. Social Issues Research Center.

[9] Gathinga, M; Ndungu, R., and Njoroge, M. (2015). Sexual Intercourse Euphemisms in the Gikuyu Language. A cognitive Linguistics Approach. In The University of Nairobi Jounal of Language and Linguistics. 20-41

[10] He, G. (2010). An Analysis of Sexism in English. In Journal of Language Teaching and Research, Volume 1, No.3, pp 332-335. Poland: Academic Publishers
[11] Hines, C. (2000). 'Rebaking the pie: The woman as dessert metaphor'. In B. Mary, Liang, A. and Sutton, L. (Eds) Reinventing Identities: The Gendered self in Discourse. Oxford: Oxford University Press. pp.145-162

[12] Hugh, A. (1991). The Kenya ceramic Jiko. A manual for stove markers. London: Immediate Technology Publishers.

[13] Kammen, D. (2001). Research, Development and Commercialization of the Kenya Ceramic Jiko and other Biomass Stores in Africa. Princeton: International Affairs Princeton University.

[14] Khajeh, Z and Abduallah, I. (2012). Persian Culinary metaphors: A cross cultural conceptualization. In Journal of Language Studies, Volume 12 (1).

[15] Kiango, J. (2003). Syntactic classification of Swahili Verbal Expressions. Africa and Asia. No 3, pp. 25-40

[16] Kinyanjui, M. and Childers, L. (1983). How to make ceramic Jiko. Nairobi: Energy Development International.

[17] Kowalczyk, Z. A. (2015) on the projection of FOODSTUFF on the macrocategory BODY PARTS. In Token: A Journal of English Linguistics Volume 4.

[18] Kowalczyk, Z., A. (2016). The Semantic History of dough, bread, bun: On how money and women go together. In Seria Filologiczna, Studia Anglica Revosiensia 13.

[19] Labovitz, G. (2008) “Is Rav’s wife a Dish? Food and Eating metaphors in Rabbinic Discourse of Sexuality and Gender relations”, In (Ed) Greenspoon, L. and Ronald, A. Studies in Jewish Civilisation, Volume 8, Love Ideal and Real- in the Jewish Tradition from the Hebrew Bible until Modern Times. Omaha: Creighton University Press.

[20] Lakoff, G. (1987). Women, Fire and Dangerous Things. What categories reveal about the mind. Chicago: University of Chicago.

[21] Lei, X. (2006). Sexism in Language. In Journal of Language and Linguistics. Volume 5, Number 1.

[22] Mmadike, B. (2014). The Igbo perception of womanhood: Evidence of sexist proverbs. Research on Humanities and Social Sciences. Volume (4), NO. 18

[23] Montashery, F. (2013). Figurative construction of Gender through metaphor and metonymy. Advances in English Linguistics (AEL), Volume 2, World Science Publishers

[24] Murashova, and Pravikora (2014). Erotisation as the basis of female metaphor in the English language. In Language and Culture 4, (28) p. 89-98

[25] Nneka, U. (2012). Linguistic Sexism. An Overview of the English Language in Everyday Discourse.In AFRREVLALIGENS, An International Journal of Language, Literature and Gender Studies. Volume (1) (1)

[26] Njoroge, R., Mukhwana, A., and Sanja, K. (2016). Calling a spade a big spoon with handle euphemisms for taboo words on Sex in Kikuyu. International Journal of Scientific Research and Innovative Technology. Volume 3, Number 5.

[27] Rodriguez, I. L (2009) of women, Bitches, Chickens and Vixens. Animal metaphors for women in English and Spanish. Culture, Language and Representations, Volume VII, pp. 77-100 
[28] Rodriguez, I. L. (2014) Are we what we eat? Food metaphors in the conceptualization of ethnic groups. Linguistik online, Volume 98, No 7. URL.

[29] Romaine, S. (2005). Language and Gender. Linguistic Anthropology. Encyclopedia of Life Support Systems (EOLSS). Developed under the auspice of UNESCO. Oxford: Eolss Publishers. Website: http://www.eolss.net

[30] Ruiz, E. and Herrero, R. (2006). The Processing of Animal-Related Expressions. Website:http://www.sepln.or g/revistaSEPLN/revista/37/36. Consulted on 12.12. 2018

[31] Posey. B. (2012). Four body types apple, banana, pear and hourglass. Ursidae: The Undergraduate Research Journal, University of Colorado. Volume 2, Number 2.

[32] Wardhugh, R. and Fuller, N. J (2015). Language, Gender and Sexuality. In R. Wardhugh and Fuller, N. Introduction to Sociolinguistics. Chichester: John Wiley and Sons.

[33] Weatherall, A. (2002). Gender, Language and Discourse. Hove: Routledge.

[34] Wenje, P. (2015). Images of women in Pakruok. (Luo Praise names). Journal of Communication and Culture. Volume 4, pp 38-59

[35] Yusuf, Y. (2000) Sexism, English and Yoruba. In Linguistik Online. Startsette, Bd, 11, Number 2

[36] Varriano, J. (2005) Fruits and Vegetables as Sexual metaphors in Late Renaissance. In Gastonomica 8: The Journal of food and culture. Volume 5, No 4. Pp 8-14 